\title{
Breast Cancer in Bedouin-Arab Patients in Southern Israel: Epidemiologic and Biologic Features in Comparison with Jewish Patients
}

\author{
Irina Lazarev*, Maayan Flaschner, David B Geffen, Samuel Ariad
}

\begin{abstract}
Background: Breast cancer (BC) is the most frequent cancer type, and the leading cause of death from cancer among women in Israel. The Bedouin-Arab (BA) population in southern Israel is characterized by a high rate of consanguinity, common hereditary disorders, and transition from a semi-nomadic, traditional society to a more sedentary and urbanized society. In this hospital-based study, the demographic and the clinicopathological characteristics of $\mathrm{BC}$ in $\mathrm{BA}$ were compared with Jewish patients. Materials and Methods: 85 BA patients treated at the Soroka Medical Center, Beer Sheba, during the years 2004-2012, were studied and compared with 180 consecutive Jewish patients treated during the year 2007. Clinicopathological features compared included age, menopausal state, number of births, a history of $\mathrm{BC}$ in first-degree relatives, tumor size (T), extent of lymphnode involvement $(\mathrm{N})$, distant metastases $(M)$, stage, grade, estrogen and progesterone receptor $(\mathrm{ER} / \mathrm{PR})$, and Her2 status. Types of treatment, relapse rate and site, as well as outcome were also studied. Cox's regression models were applied for studying disease-free, and overall survival. Results: Compared with Jewish patients, BA patients were younger (average age $49 \pm 12$ yrs $v s 59 \pm 13, \mathrm{p}<0.001$ ), had a lower rate of $\mathrm{BC}$ in first-degree relatives $(\mathrm{p}<0.001)$, and a larger number of births $(6 \pm 4.2$ vs $2.5 \pm 1.9, \mathrm{p}<0.001)$. BA patients had larger tumors $(\mathrm{p}=0.02)$, more extensive lymph-node involvement $(\mathrm{p}=\mathbf{0 . 0 0 2})$, and more advanced stage $(\mathrm{p}=0.003)$. Grade, $\mathrm{ER}$, PR, and Her2 status were similar in the two ethnic groups. Relapse type was most commonly systemic in BA patients $(p=0.05)$, and loco-regional in Jewish patients $(p=0.02)$. Median survival was 63 , and 35 months for Jewish and BA patients, respectively (log-rank test, $\mathrm{p}=0.02)$. In Cox multivariate analysis, stage and PR status (HR-0.14, p<0.0001; HR-3.11, p=0.046), but not ethnicity, influenced overall survival. Conclusions: $B C$ presents a decade earlier, and with more advanced disease in BA compared with Jewish patients. Biologic parameters including grade, ER, PR, and Her2 status were similar in both groups. Although prognosis was worse in BA than in Jewish patients, it was affected only by stage and PR status, but not by ethnicity.
\end{abstract}

Keywords: Breast cancer - Bedouin arab - prognosis - stage - age.

Asian Pac J Cancer Prev, 15 (18), 7533-7537

\section{Introduction}

Breast cancer $(\mathrm{BC})$ is the most frequent cancer type and the leading cause of death among women in Israel (BaronApel, Israel Center for Disease Control) a. Time-trends in the incidence of BC have been different in Jewish and Israeli-Arab populations. Following a steady rise over a few decades, the incidence of BC in Jews decreased by $3 \%$ from 1996 through 2007. In contrast, the incidence of $\mathrm{BC}$ in Israeli-Arabs continued to increase by $98 \%$ over the same time-period. Age-adjusted incidence rates in Jews and Israeli-Arabs in 2010 reached levels of 91, and of 53 cases per 100,000 per year, respectively (Israel Cancer Registry, Jerusalem).

Bedouin-Arabs (BA), who are part of the Israeli-Arab population of Israel, reside in the Negev, a desert and a semidesert region of southern Israel. BA account for almost $20 \%$ of the one-million population of the Negev (Israel Central Bureau of Statistics), and almost all Israeli-Arabs living in the Negev are BA. The genetics of BA of the Negev resembles that of the population of the Arabian Peninsula (Nebet et al., 2001) supporting the view that the BA population of the Negev originated in the Arabian Peninsula (Bailey et al., 1980) Numerous hereditary disorders, a few of which are peculiar to the BA population of the Negev have been described (Kenan et al., 2002; Zlotogora et al., 2013), and are related to a high rate of consanguinity in this population (Kenan et al., 2002).

In recent decades, the BA population of the Negev has undergone transition from a semi-nomadic, traditional society to a more sedentary and urbanized society. This changeover has been associated with altered lifestyle and 
Irina Lazarev et al

nutrition including abandonment of traditional foods for "modern foods" (Fraser et al., 2001), and use of unfortified white-flour bread instead of whole wheat bread as the main dietary staple (Abu-Saad et al., 2009). Compared with Jewish women, BA women have a higher rate of obesity and age-adjusted body mass index (Fraser et al., 2008), and a higher saturated fatty acid composition in human milk (Silberstein et al., 2013). Since genetics, hormones, and environment may all interact to cause BC, the high prevalence of consanguinity, combined with a rapid changeover in lifestyle and nutrition, make the $\mathrm{BA}$ population of the Negev highly attractive for studying BC.

\section{Materials and Methods}

Study population

Following approval by the Institutional Review Board, we searched our registry and computerized database to identify newly-diagnosed BC patients who were referred to the oncology clinic at the Soroka University Medical Center (SUMC), Beer Sheba. Patients with histological diagnosis of $\mathrm{BC}$ other than invasive ductal carcinoma, or a previous history of another primary tumor were excluded from the study. Only patients for whom complete clinical and pathologic data were available were included in the study. The group of BA patients consisted of all BA patients referred to the oncology clinic from January $1^{\text {st }} 2004$ to December $31^{\text {st }} 2012$. This group of patients included 85 patients who comprised $3.5 \%$ of the total $\mathrm{BC}$ patients referred to SMC during the study period. The control group consisted of 180 consecutive Jewish patients referred to the oncology clinic during one year, from January $1^{\text {st }} 2007$ to December $31^{\text {st }} 2007$. Patients' medical records were retrospectively reviewed and demographic and clinical data were recorded. Baseline data included age, parity, menstruation status, place of birth (for Jewish patients), a history of breast cancer in first-degree relatives, tumor size $(\mathrm{T})$, lymph-node involvement $(\mathrm{N})$,

Table 1. Demographic and Clinicopathological Characteristics of BC Patients: (1) BA patients, (2) Jewish patients.

\begin{tabular}{|c|c|c|c|c|c|}
\hline \multicolumn{2}{|c|}{ Demographics and clinicopathological characteristics } & \multicolumn{3}{|c|}{ Study population } & \multirow[t]{2}{*}{$\mathrm{p}$ value* } \\
\hline & & $\begin{array}{c}\text { Bedouin-Arab } \\
\mathrm{N}=85 \mathrm{n}(\%)\end{array}$ & $\begin{array}{c}\text { Jewish } \\
\mathrm{N}=180 \mathrm{n}(\%)\end{array}$ & $\begin{array}{c}\text { All } \\
\mathrm{N}=265 \mathrm{n}(\%)\end{array}$ & \\
\hline \multirow[t]{3}{*}{ Ethnic origin (for Jewish patients only) } & Ashkenazi & & $103(57)$ & & \\
\hline & Sephardic & & $63(35)$ & & \\
\hline & Israel-born & & $15(8)$ & & \\
\hline \multirow[t]{3}{*}{ Age at diagnosis (years) } & Mean \pm SD** & $49 \pm 12$ & $59 \pm 13$ & $56 \pm 14$ & $<0.0001$ \\
\hline & Median & 49 & 58 & 54 & \\
\hline & Range & $22-84$ & $31-90$ & $22-90$ & \\
\hline \multirow[t]{3}{*}{ First-degree family history of breast cancer } & Yes & $4(4)$ & $36(20)$ & $40(15$ & 0.009 \\
\hline & No & $55(65)$ & $139(77)$ & $194(73)$ & \\
\hline & Unknown & $26(31)$ & $5(3)$ & $31(12)$ & \\
\hline \multirow[t]{3}{*}{ Number of births } & Mean \pm SD** & $6 \pm 4.2$ & $2.5 \pm 1.9$ & $3.6 \pm 3.2$ & $<0.0001$ \\
\hline & Median & 6 & 2 & 3 & \\
\hline & Range & 0-19 & $0-13$ & 0-19 & \\
\hline \multirow[t]{3}{*}{ Menstruation status } & Premenopausal & $36(46)$ & $44(26)$ & $80(32)$ & $<0.0001$ \\
\hline & Perimenopausal & $19(24)$ & $17(10)$ & $36(14)$ & \\
\hline & Postmenopausal & $28(30)$ & $111(65)$ & $135(54)$ & \\
\hline \multirow[t]{4}{*}{ Tumor size $(\mathrm{T})$} & $\mathrm{T} 1$ & $25(29)$ & $84(47)$ & $109(42)$ & 0.023 \\
\hline & $\mathrm{T} 2$ & $26(31)$ & $57(32)$ & $83(32)$ & \\
\hline & $\mathrm{T} 3$ & $26(31)$ & $31(17)$ & $57(22)$ & \\
\hline & $\mathrm{T} 4$ & $5(6)$ & $7(4)$ & $12(5)$ & \\
\hline \multirow[t]{3}{*}{ Nodal status (N) } & No & $32(40)$ & $92(52)$ & $124(48)$ & 0.005 \\
\hline & 1-3 lymph-nodes & $27(33)$ & $66(37)$ & $93(36)$ & \\
\hline & $\varnothing 4$ lymph-nodes & $22(27)$ & $20(11)$ & $42(16)$ & \\
\hline \multirow[t]{2}{*}{ Metastasis } & Yes & $7(9)$ & $13(7)$ & $20(8)$ & 0.69 \\
\hline & No & $74(91)$ & $167(93)$ & $241(92)$ & \\
\hline \multirow[t]{4}{*}{ Stage } & 1 & $16(28)$ & $60(23)$ & $76(29)$ & 0.003 \\
\hline & 2 & $29(34)$ & $74(41)$ & $100(39)$ & \\
\hline & 3 & $33(39)$ & 34 (19) & $67(25)$ & \\
\hline & 4 & $7(8)$ & $12(7)$ & $19(7)$ & \\
\hline \multirow[t]{4}{*}{ Grade } & Well-differentiated (G1) & $12(14)$ & $38(21)$ & $50(19)$ & 0.54 \\
\hline & Moderately-differentiated (G2) & $22(26)$ & $48(27)$ & $70(26)$ & \\
\hline & Poorly-differentiated (G3) & $22(26)$ & $41(23)$ & $63(24)$ & \\
\hline & Unknown & $29(34)$ & $53(29)$ & $82(31)$ & \\
\hline \multirow[t]{2}{*}{ ER status } & Positive & $65(77)$ & $142(79$ & $207(78)$ & 0.38 \\
\hline & Negative & $20(24)$ & $38(21)$ & $58(22)$ & \\
\hline \multirow[t]{2}{*}{ PR status } & Positive & $44(52)$ & $103(57)$ & $147(56)$ & 0.4 \\
\hline & Negative & $41(48)$ & 77 (43) & $118(45)$ & \\
\hline \multirow[t]{2}{*}{ Her2 status } & Positive & $16(19)$ & $49(27)$ & $65(25)$ & 0.15 \\
\hline & Negative & $69(81)$ & $128(73)$ & $197(74)$ & \\
\hline \multirow[t]{2}{*}{ Hormone receptor pattern } & Yes & $64(75)$ & $145(81)$ & 209 (79) & 0.56 \\
\hline & No & $21(25)$ & $35(19)$ & $56(21)$ & \\
\hline \multirow[t]{2}{*}{ Triple negative" pattern } & Yes & $23(13)$ & $11(13)$ & $34(13)$ & 1 \\
\hline & No & $157(87)$ & $74(87)$ & $231(87)$ & \\
\hline \multirow[t]{3}{*}{ Her2 positive" pattern } & Her2 positive, all & 16 & 49 & 65 & 0.06 \\
\hline & Her2 positive, ER-positive & $6(38)$ & $35(71)$ & $41(63)$ & \\
\hline & Her2 positive, ER-negative & $10(62)$ & $14(29)$ & $24(37)$ & \\
\hline
\end{tabular}


and presence or absence of distant metastases (M), stage according to 2002 AJCC classification system (Singletary et al., 2002), grade according to Scarff-Bloom-Richardson system (Elston et al., 1991), expression of estrogen and progesterone receptors, and Her2 status. Whenever pathologic data was available in addition to clinical data, the pathologic data was determinant for stage. Treatment data consisted of type of surgery for BC, type of adjuvant treatment (chemotherapy, hormonal, or radiotherapy). Outcome measures included most recent status, and site of relapse.

\section{Statistical analysis}

Demographic and clinical parameters were presented by descriptive statistics. The $\mathrm{x}^{2}$ and the Mann-Whitney $\mathrm{U}$ tests were used as appropriate. All statistical tests were two-sided, and statistical significance was defined at a level $p$ less of than 0.05 . Overall and disease free survival (OS and DFS) was defined as the time from diagnosis to time of death from any cause, and time of documented local or distant recurrence of tumor, respectively. Cox proportional hazard models were used to compare DFS and OS between groups. The following variables were converted into dichotomic parameters: Age ( $>50$ years $v s<50$ years), ethnicity (Jewish $v s$ Bedouin-Arab), tumor (3-4 vs 1-2), node (-ve vs $\pm v e$ ), stage (1-2 vs 3-4), grade (1-2 vs 3), ER (-ve vs \pm ve), PR (-ve vs \pm ve), and Her2 status ( $\pm v e v s-v e)$. Statistically-significant parameters in the univariate analyses were included in the multivariate Cox's analyses, and Kaplan-Meier estimates were calculated. Statistical analyses were conducted using SPSS version 20 for windows (SPSS inc., Chicago, Il USA).

\section{Results}

Table 1 summarizes the frequencies of baseline characteristics of all $\mathrm{BC}$ patients by ethnicity. A total of 265 patients were included in the study. Out of these, 85 patients were BA while 180 patients belonging to the control group were Jewish. Most Jewish patients (103 patients, $57 \%$ ) were of the Ashkenazi extraction, and only 15 patients $(8 \%)$ were Israeli-born. The average age of BA patients was 49 years (range 22 to 84 years), while the average age of Jewish patients was 59 years (range 31 to 90 years, $\mathrm{p}<0.0001$ ). First degree family history of $\mathrm{BC}$ was more common in the Jewish than the BA group $(p<0.0001)$. The average number of births in the BA group was 6 (range 0 to 19), and 2.5 (range 0 to 13) in the Jewish group $(\mathrm{p}<0.0001)$. A higher proportion of BA patients were pre-or perimenopausal than Jewish patients $(\mathrm{p}<0.0001)$. BA patients had larger tumors than Jewish patients $(p=0.024)$, had more extensive lymph-node involvement $(\mathrm{p}=0.002)$, a higher frequency of metastatic disease $(\mathrm{p}=0.013)$, and more advanced stage $(\mathrm{p}=0.003)$. No difference was observed in regard to grade, estrogen or progesterone receptor, or Her2 status between the two groups. Table 2 shows types of treatment and outcome results in BA compared with Jewish patients. More BA patients received neo-adjuvant chemotherapy compared with Jewish patients $(p<0.0001)$. A higher proportion of BA patients tended to undergo mastectomy than Jewish patients $(\mathrm{p}=0.082)$, while a higher proportion of Jewish than BA patients showed a trend for receiving adjuvant chemotherapy $(p=0.078)$. There was no difference between the two groups in regard to receiving hormonal treatment. Systemic relapse was more common in the BA than the Jewish group $(\mathrm{p}=0.020)$, while the Jewish group showed a trend towards having locoregional

Table 2. Treatments and Outcome of BC Patients: (1) BA patients, (2) Jewish patients

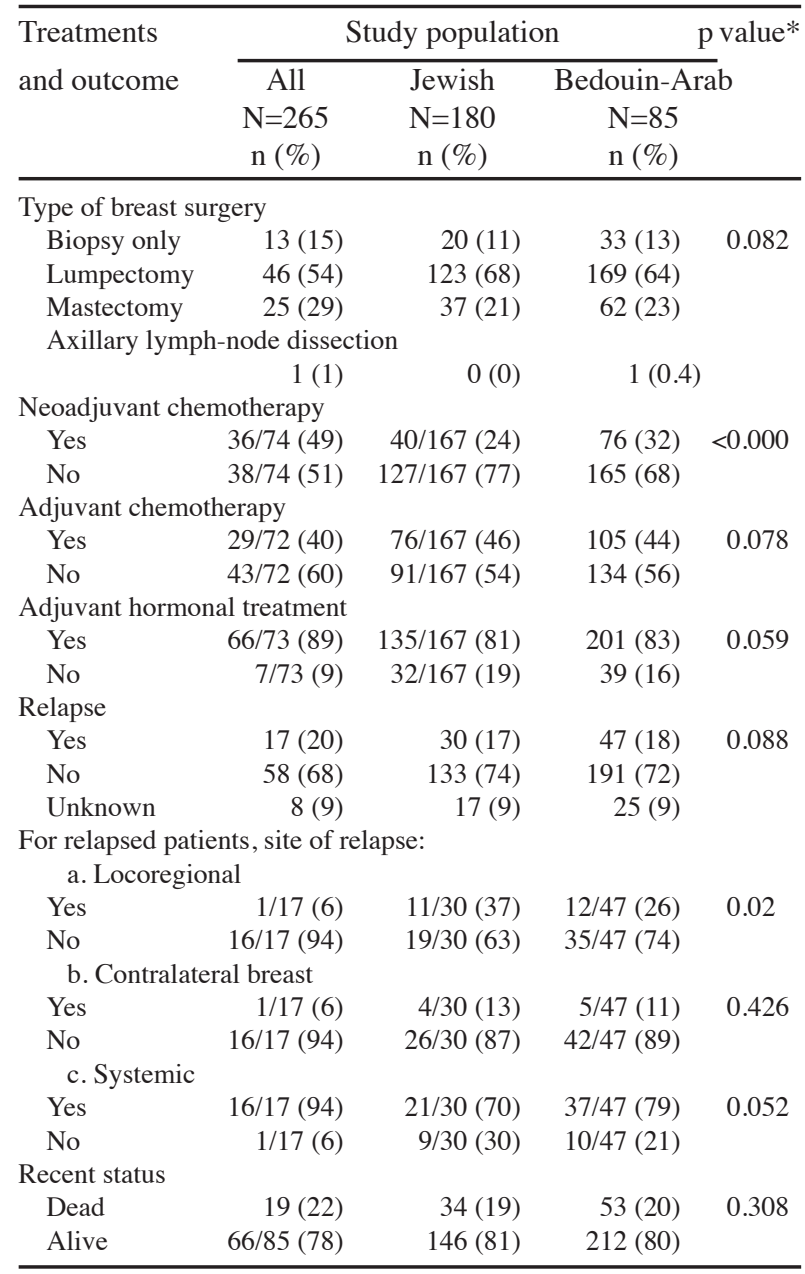

Table 3. Cox's Univariate Analysis of Factors Predicting Overall Survival in BC Patients

\begin{tabular}{lccc}
\hline Parameter & HR* & $95 \%$ CI** & p value \\
\hline Stage & 2.68 & $2.00-3.58$ & $<0.0001$ \\
Age & 1.06 & $1.04-1.09$ & $<0.0001$ \\
Jewish vs Bedouin-Arab & 0.33 & $0.17-0.64$ & $<0.001$ \\
\hline
\end{tabular}
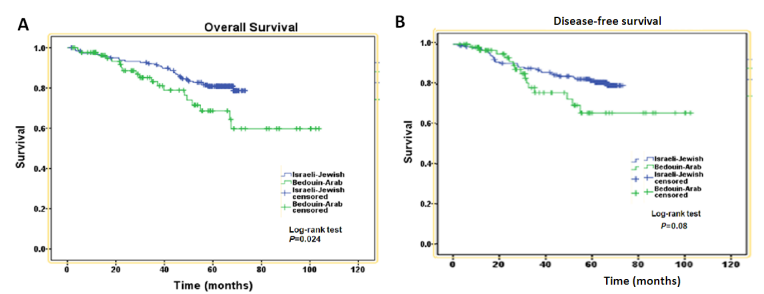

Figure 1. Kaplan-Meier Survival Curves Showing Survival of BA Patients Compared with Jewish Patients: (A) Overall Survival, (2) Disease-free Survival 
relapse compared with the BA group ( $\mathrm{p}=0.052)$. In Cox's univariate analysis, the following parameters affected OS: stage (HR-0.19, $\mathrm{p}=0.02)$, and PR status (HR-3.15, $\mathrm{p}=0.05)$, but not ethnicity. Results of Cox's univariate analysis are shown in Table 3. Also in Cox multivariate analysis, stage and PR status (HR-0.14, p<0.0001; HR-3.11, p=0.046), but not ethnicity influenced overall survival. In Cox's univariate analysis, none of these parameters affected PFS. Kaplan-Meier, overall and progression-free survival curves are shown in Figure 1.

\section{Discussion}

We have studied the characteristics of BC in, BA and Jewish patients, two different ethnic groups residing in the same geographical region of southern Israel. The average age at presentation of BA patients was 49 years, a decade earlier than Jewish patients. A similar difference in the average age of BC patients between Israeli-Arab women and Jewish patients has previously been reported in patients residing in the Jerusalem area (Nissan et al., 2004), and in northern Israel (Zidan et al., 2012). Several studies reported a similar pattern of earlier diagnosis of BC in Arab countries (Chouchane et al., 2013; Slaou et al., 2014). A younger age of BC patients has also been reported from many developing countries (Amaya-Ruiz et al., 2014; Keramtinia et al., 2014). A comparable difference in age-distribution of BC in women has been observed in minority populations in other countries (Hemminki et al., 2011).

Younger onset, around the age of 50 years, of $\mathrm{BC}$ in populations with low BC prevalence compared with lateonset of $\mathrm{BC}$ in high-risk populations may be explained by several ways: $i$ ) under-representation of $\mathrm{BC}$ in the elderly population due to under-diagnosis or incomplete registration, ii) a difference in $\mathrm{BC}$ biology, and iii) a high proportion of younger people in populations with low BC prevalence. Since all citizens of Israel, including BAs receive government mandated health services funded by an income-related health tax, under-diagnosis in the elderly BA patients seems unlikely. In addition, since SMC is the only medical center providing both primary and tertiary services to cancer patients in southern Israel, incomplete registration of BA patients is also highly improbable. The finding of a younger mean age at diagnosis in BA (which is also the case with respect to the total Israeli-Arab population) may be a result of a different age-pyramid in Israeli-Arabs in general and BA in particular, over-representing younger age groups and under-representing older age groups. Thus, younger age at diagnosis may merely reflect a larger proportion for the younger age groups and a much smaller proportion for the older age groups in the total population, and consequently also among the patients. Similar findings in regard to $\mathrm{BC}$ and age distribution were previously described in the total Arab population in Israel (Keynan-Boker et al., 2013). Tumor characteristics in regard to grade, estrogen and progesterone receptors, and Her 2 in our study were similar in both ethnic groups, making a difference in BC biology a less plausible explanation.

In contrast to Jewish patients, BA patients were diagnosed with larger tumors, more extensive lymph-node involvement, and more advanced stage. Also the rate of systemic relapse was much higher in BA than in Jewish patients. Survival analysis has shown worse outcome of BA patients with significantly shorter OS compared with Jewish patients. This finding of more advanced tumor presentation of $\mathrm{BC}$ in $\mathrm{BA}$ patients concurs with two previous reports on Palestinian patients residing in the Jerusalem area, and in Arab patients residing in northern Israel (Zidan et al., 2012). A late stage at presentation and locally-advanced BC has typically been reported in studies from Arab countries (Ortashi, 2013), and has been ascribed in these studies to failure to seek medical attention for early but palpable BC (Donnelly et al., 2013). Cultural reluctance to participate in screening mammography programs in the Arab population has been mentioned as a major impediment for early diagnosis of $\mathrm{BC}$ in these countries (Bener et al., 2010). The policy of the national $\mathrm{BC}$ screening program in Israel is to recommend bi-annual mammography to women at average risk at age 50-74 years, and annual mammography to women at increased familial risk from age 40 . The program estimates that $72 \%$ of Israeli women have undergone the study within the past two years. Screening rates among Arab women (including BA women) have steadily increased, and at present are nearly identical to that of Jewish women. The relatively young age of $\mathrm{BC}$ presentation in BA women, combined with the late stage at presentation and locallyadvanced $\mathrm{BC}$ in this population suggest that the national recommendations for $\mathrm{BC}$ screening starting at the age of 50 years are less effective in detecting early $\mathrm{BC}$ in BA women of younger age.

As previously mentioned, the pattern of $\mathrm{BC}$ biologic parameters, including estrogen and progesterone receptor status, Her2 expression, and grade in our study was similar in BA and Jewish patients. The finding of common biologic parameters in BC in BA and in Jewish patients is in contrast to a report on Israeli-Arab patients residing in northern Israel that described a higher proportion of high-grade, triple-negative or Her2-positive tumors in Israeli-Arab compared with Jewish patients (Zidan et al., 2012). As in our study, the proportion of hormone receptor-positive $\mathrm{BC}$ in Palestinian patients residing in the district of Jerusalem was similar to that observed in Jewish patients (Nissan et al., 2004). A high proportion of BC showing aggressive patterns including high-grade, triple-negative or Her2-positive tumors was reported in BC patients from Saudi Arabia. Saudi women had almost 14-folder lower risk of developing low-grade BC than did Swiss patients, suggesting a high-grade pathway in BC development in Saudi women (Al-Kuraya et al., 2005). The difference in tumor biology between BA patients in southern Israel and patients from Saudi Arabia emphasizes the importance of different acquired factors in the development of $\mathrm{BC}$ between these two populations.

Despite a high prevalence of consanguinity in the BA population, BA patients in our study had a lower rate of BC in first-degree relatives compared with Jewish patients. Although under-reporting of a family history of $\mathrm{BC}$ in BA women must be considered, it is more likely that consanguinity has no effect or could have a mild 
protective effect on $\mathrm{BC}$ risk in $\mathrm{BA}$ women. This finding concurs with a report describing a lower risk of $\mathrm{BC}$ in Arab women whose parents were consanguineous compared with those whose parents were non-consanguineous (Kenan et al., 2002).

The number of births in BA patients in our study was 2.5 fold larger than in Jewish patients. Reproductive factors have long been associated with increased risk of developing BC. The relative lower prevalence of $\mathrm{BC}$ in the Israeli-Arab compared with the Jewish population in the past could be related to a higher birth rate in Israeli-Arabs. Because of the relatively small number of BA patients included in our study, we could not study the time-trend in the incidence of $\mathrm{BC}$ in BA patients during the study period. Lifestyle and nutrition have changed in the BA population of the Negev in recent years. In addition to a declining birth rate, BAs' diet has become rich in carbohydrates (Fraser et al., 2001; 2008), and the rate of obesity in BA women has increased (Abu-Saad et al., 2009). As a result of all these factors, it is anticipated that the prevalence of $\mathrm{BC}$ in $\mathrm{BA}$ women will rise, following a similar pattern to that observed in the Jewish population.

Survival analysis has shown worse outcome of BA patients with significantly shorter OS compared with Jewish patients. Also the rate of systemic relapse was much higher in BA than in Jewish patients. However, survival rates in the two populations were similar after adjusting for stage and age, suggesting a common biology of $\mathrm{BC}$ in the two populations. Survival analysis was based on different follow-up periods for the two populations: a relatively widely-distributed follow-up period according to the year of diagnosis for BA patients, and a six-year follow-up period for Jewish patients. Despite a relatively short follow-up period for some BA patients diagnosed in recent years, it is unlikely this limitation could significantly affect survival analysis in our study.

In summary, we compared BC in two distinct populations living in southern Israel. $\mathrm{BC}$ was diagnosed in BA women a decade earlier than in the Jewish population. Biologic parameters were however similar in both populations, a finding that differs from that described in both Israeli-Arab patients residing in northern Israel, and patients from Saudi Arabia. Because of life-style changes in $\mathrm{BA}$ in recent years, the prevalence of $\mathrm{BC}$ in $\mathrm{BA}$ women is expected to rise, following a similar pattern to that observed in the Jewish population.

\section{References}

Abu-Saad K, Shai I, Kaufman-Shriqui V, et al (2009). Bread type intake is associated with lifestyle and diet quality transition among Bedouin Arab adults. Br J Nutrition, 102, 1513-22.

Al-Kuraya K, Schraml P, Sheikh S, et al (2005). Predominance of high-grade pathway in breast cancer development of Middle East women. Mod Pathol, 18, 891-7.

Al-Tamini DM, Shawarby MA, Ahmed A, et al (2010). Protein expression profile and prevalence pattern of the molecular classes of breast cancer: a Saudi population based study. BMC Cancer, 10, 223.

Bailey C (1980). Dating the arrival of the Bedouin tribes in Sinai and the Negev. J Econ Soc Hist Orient, 28, 21-4.

Baron-Apel O (1999). Breast cancer. In: Green M, eds. The
DOI:http://dx.doi.org/10.7314/APJCP.2014.15.18.7533

Breast Cancer in Bedouin-Arab Patients in Southern Israel.

state of health in Israel in 1999. Jerusalem: Israel Center for Disease control, 213, 91-5.

Bener A, Ayoubi HR, Ali AI, et al (2010). Does consanguinity lead to decreased incidence of breast cancer? Cancer Epidemiol, 34, 413-8.

Chouchane L, Boussen H, Sastry KS (2013). Breast cancer in arab populations: molecular characteristics and disease management implications. Lancet Oncol, 10, 417-24.

Donnelly TT, Khater AH, Al-Bader SB, et al (2013). Arab women's breast cancer screening practices: a literature review. Asian Pac J Cancer Prev, 14, 4519-28.

Elston CW, Ellis IO (1991). Pathologic prognostic factors in breast cancer. I. the value of histological grades in breast cancer. experience from a large study with long-term followup. Histopathology, 19, 403-10.

El Saghir NS, Seoud M, Khalil MK, et al (2006). Effects of young age at presentation on survival in breast cancer. $B M C$ Cancer, 6, 194.

Fraser D, Abu-Saad k, Abu-Shareb H (2001). The relative importance of traditional and "modern" foods for israeli negev bedouins. a population in transition. Nutr Metab Cardiovasc Dis, 11, 66-9.

Fraser D, Bilenko N, Vardy H, et al (2008). Differences in food intake and disparity in obesity rates between adult Jews and Bedouins in southern Israel. Eth Dis, 18, 13-8.

Hemminki K, Mousavi SM, Sundquist J, et al (2011). Does the breast cancer age at diagnosis differ by ethnicity? a study on immigrants to sweden. The Oncologist, 16, 146-54.

Israel Cancer Registry, Jerusalem. http://www.old.health.gov.il/ download/pages/shad2001-final.pdf

Israel Central Bureau of Statistics. Statistical Abstract of Israel 2013-No 64. Society and Population. http://www.cbs.gov. il/reader

Keinan-Boker L, Baron-Epel O, Fishler Y, et al (2013). Breast cancer trend in Israeli Jewish and Arab women, 1996-2007. Eur J Cancer Prev, 22, 112-20.

Kenan G, Burck L (2002). Trends in patrilineal parallel first cousin marriages among israeli-arabs. Ann Hum Biol, 29, 398-413.

Nebet A, Brinkmann B, Majumder PP et al (2001). The y chromosome of jews as part of the genetic landscape of the middle-east. Am J Hum Genet, 69, 1095-112.

Nissan A, Spira RM, Hamburger T et al (2004). Clinical profile of breast cancer in arab and jewish women in the Jerusalem area. Am J Surg, 188, 62-7.

Ortashi O (2013). Gynecological cancer services in Arab countries: present scenario, problems and suggested solutions. Asian Pac J Cancer Prev, 14, 2147-50.

Singletary SE, Allred C, Ashley P et al (2002). Revision of the american joint committee on cancer staging system for breast cancer. J Clin Oncol, 20, 3628-36.

Silberstein T, Burg A, Blumenfeld J, et al (2013). Saturated fatty acid composition in human milk in Israel. a comparison between Jewish and Bedouin women. IMAJ, 15, 156-9.

Slaoui M, Razine R, Ibrahimi A, et al (2014). Breast cancer in Morocco: a literature review. Asian Pac J Cancer Prev, 15, 1067-74.

Zidan J, Sikorsky N, Basher W, et al (2012). Differences in pathological and clinical features of breast cancer in Arab as compared to Jewish women in Northern Israel. Int $J$ Cancer, 131, 924-9.

Zlotogora J (2013). Mendelian disorders in the non-jewish population of israel. publication of the department of community genetics, public health services, ministry of health, israel. http://www.health.gov.il/Subjects/Genetics/ Documents/book_jews.pdf 